УДК 691.396

\title{
ОЦЕНКА ДЛИТЕЛЬНОСТИ ОПТИЧЕСКОГО ИМПУЛЬСА С ПРЯМОУГОЛЬНЫМ ПРОФИЛЕМ ИНТЕНСИВНОСТИ НЕИЗВЕСТНОЙ ВЫСОТЫ“
}

ТРИФОНОВ А. П., МИЛОГОРОДСКИЙ А. А.

Воронежский государственный университет,

Россия, Воронеж, 394006, Университетская пл., д. 1

\begin{abstract}
Аннотация. Выполнены синтез и анализ квазиправдоподобного и максимально правдоподобного алгоритмов оценки длительности. Найдены потери в точности квазиправдоподобной оценки вследствие априорного незнания интенсивности импульса. Установлено, что точность оценки максимального правдоподобия длительности асимптотически инвариантна к наличию априорной информации об интенсивности импульса.
\end{abstract}

Ключевые слова: квазиправдоподобия оценка; оценка максимального правдоподобия; рассеяния оценок; априорная параметрическая неопределенность

Модель оптического импульса с прямоугольным профилем интенсивности используется во многих приложениях оптической связи и локации [1-6]. Рассмотрим оценку неизвестной длительности оптического импульса с прямоугольным профилем интенсивности на фоне шума. Будем считать, что на интервале времени $[0, T]$ наблюдается реализация пуассоновского процесса $\pi(t)$ с интенсивностью

$$
\begin{gathered}
\lambda(t)=\beta_{0} s(t)+\alpha, \\
s(t)= \begin{cases}1, & 0 \leq t \leq \tau_{0}, \\
0, & t<0, t>\tau_{0},\end{cases}
\end{gathered}
$$

где $\alpha$ - априори известная интенсивность оптического фона, $\beta_{0}$ - неизвестная интенсивность импульса, $\tau_{0}-$ неизвестная длительность импульса, которая может принимать зна- чения из интервала $\left[T_{1}, T_{2}\right]$, причем $0<T_{1}<T_{2}<$ $T$.

Если известна интенсивность $\beta_{0}$, то для оценки длительности импульса $\tau_{0}$ возможно использовать метод максимального правдоподобия [7]. Согласно этому методу, оценка длительности определяется как положение наибольшего максимума логарифма функционала отношения правдоподобия (ФОП).

Выражение для логарифма ФОП [8] имеет вид

$$
L_{0}(\tau)=\pi_{\tau} \ln \left(1+\beta_{0} / \alpha\right)-\beta_{0} \tau,
$$

где $\pi_{\tau}=\int_{0}^{\tau} \mathrm{d} \pi(t)$. Соответственно, оценка максимального правдоподобия (ОМП) определяется как:

$$
\tau_{m}=\operatorname{argsup} L_{0}(\tau), \tau \in\left[T_{1}, T_{2}\right] .
$$

\footnotetext{
* Исследование выполнено за счет гранта Российского научного фонда (проект № 15-11-10022).
} 


\section{БИБЛИОГРАФИЧЕСКИЙ СПИСОК}

1. Шереметьев А. Г. Статистическая теория лазерной связи / А. Г. Шереметьев. - М. : Связь, 1971. $-264 \mathrm{c}$

2. Волохатюк B. A. Вопросы оптической локации / В. А. Волохатюк, В. М. Кочетков, Р. Р. Красовский. - М. : Сов. радио, 1971. - $256 \mathrm{c.}$

3. Гальярди Р. М. Оптическая связь / Р. М. Гальярди, Ш. Карп. - М. : Связь, 1978. — 424 с.

4. Воробьев В.И. Оценка координат источника оптического излучения с прямоугольным профилем интенсивности / В. И. Воробьев // Оптико-механическая промышленность. - 1978. — № 4. - С. 14-16.

5. Воробьев В. И. Оптическая локация для радиоинженеров / В. И. Воробьев. - М. : Радио и связь, 1983. $-176 \mathrm{c}$.

6. Овчинникова T. М. Обнаружение и оценка момента изменения неизвестной интенсивности пуассоновского потока. I / Т. М. Овчинникова, А. П. Трифонов // Автоматика и телемеханика. - 1999. - № 1. C. 66-76. - Режим доступа : http://mi.mathnet.ru/at24.

7. Куликов Е. И. Оценка параметров сигналов на фоне помех / Е. И. Куликов, А. П. Трифонов. - М. : Сов. радио, 1978. - $296 \mathrm{c}$.

8. Большаков И. А. Прикладная теория случайных потоков / И. А. Большаков, В. С. Ракошиц. - М. : Сов. радио, 1978. - 248 с.

9. Мудров В.И. Методы обработки измерений. Квазиправдоподобные оценки / В. И. Мудров, В. Л. Кушко. - М. : Радио и связь, 1983. - 304 с.

10. Стратонович Р. Л. Избранные вопросы теории флюктуации в радиотехнике / Р. Л. Стратонович. - М. : Сов. радио, 1961. - 550 с.

11. Сосулин Ю. Г. Теория обнаружения и оценивания стохастических сигналов / Ю. Г. Сосулин. - М. : Сов. радио, 1978. - 320 с.

12. Трифонов А. П. Статистические свойства высоты и положения абсолютного максимума марковского случайного процесса типа Башелье / А. П. Трифонов, Ю. Э. Корчагин, М. Б. Беспалова // Вестник Воронежского государственного университета. Серия: Физика. Математика. — 2014. — № 4. - С. 35-43. — Режим доступа : hysmath\&year=2014\&num=04\&f name=2014-04-07. 